\title{
RESENHA DO DOCUMENTÁRIO “A COBERTA D'ALMA - UM RITUAL PARA OS MORTOS DE OSÓRIO"
}

Cristian Leandro Metz ${ }^{1}$

No contexto das produções audiovisuais, o gênero documentário surge como forma de reconstrução da realidade, pois permite um ponto de vista particular do documentarista em relação ao que é abordado, marca particular do seu caráter autoral. O documentário “A Coberta d'Alma - Um ritual para os mortos de Osório" retrata este ritual de passagem, por meio de depoimentos e reconstituição de fatos.

A Coberta d'Alma consiste na personificação da identidade do/a recémfalecido/a num parente ou amigo próximo, por meio da utilização de uma muda completa de roup ${ }^{2}$ por este vivo que, vestindo aquela roupa, libera a alma do corpo. Os praticantes do rito acreditam que aquela roupa com a qual o morto é enterrado, apodrece junto com a matéria e, dessa forma, a alma se desprende nua do corpo; para que a alma não se apresente nua perante Deus, é realizado o ritual da Coberta d'Alma. Desse modo, além de vestir a alma do falecido e de liberar a alma do corpo, a prática do ritual mantém viva a memória daquele falecido no seu seio familiar e social, por meio daquela pessoa que vestiu a roupa da Coberta d'Alma. A pessoa escolhida para vestir a Coberta d'Alma, além do já mencionado, passa a contar também com o carinho e o cuidado dispensado ao falecido, enquanto vivo, pela sua família.

Vencedor do $1^{\circ}$ prêmio DOCTV, o documentário "A Coberta d'Alma, um ritual para os mortos de Osório" foi realizado entre dezembro de 2003 e março de 2004 sendo apresentado, em rede nacional, na faixa DOCTV da TV Cultura no mês de agosto de 2004; desde a sua realização, o documentário já foi reprisado inúmeras vezes.

Seguindo uma tendência observacionista ${ }^{3}$ para a elaboração do argumento e de posse de um roteiro semiestruturado para as entrevistas, os depoimentos são narrados a partir do contato desses depoentes/narradores com o rito funerário em questão. Além disso, a produção conta com o momento de reconstituição da prática do ritual, momento em que a população local registra, reconstrói e apresenta essa prática funerária para o Brasil, envolto por uma aura mítica e sagrada que envolve a prática de rituais funerários.

\footnotetext{
${ }^{1}$ Universidade FEEVALE, Brasil.

${ }^{2}$ Utilizo nesta resenha a nomenclatura "roupa" para o caso da veste usada para a prática do ritual. (Nota do Autor).

3 Tendência do desenvolvimento de audiovisuais do gênero documentário muito difundido na década de 1960, mas presente muito fortemente na atualidade. (Nota do autor)
} 
Para a parte do roteiro onde são narradas as vivências da prática da Coberta d'Alma, foram localizadas pessoas que tinham por hábito a realização do ritual; são, pelo menos, 10 testemunhos que trazem, em momentos de recordação e recheados de emoção, a vivência deste rito funerário no seu seio familiar ou na sua comunidade. Nota-se que esses depoimentos são gravados nas casas dos/as depoentes e percebe-se que os/as mesmos/as sentem-se à vontade perante a câmera. Os/as depoentes não falam olhando para a câmera, não "encaram" o público. Nota-se, também, a interferência de uma voz (que provavelmente é do diretor do documentário) direcionando questões a serem respondidas/narradas pelos/as depoentes.

Além dos testemunhos dos/as moradores/as da cidade, percebe-se a busca de aporte teórico com pesquisadoras, historiadoras e antropólogas sobre as práticas de ritos funerários e, principalmente, sobre a realização da Coberta d'Alma; as falas dessas estudiosas do assunto foram captadas em estúdio (figura 1).
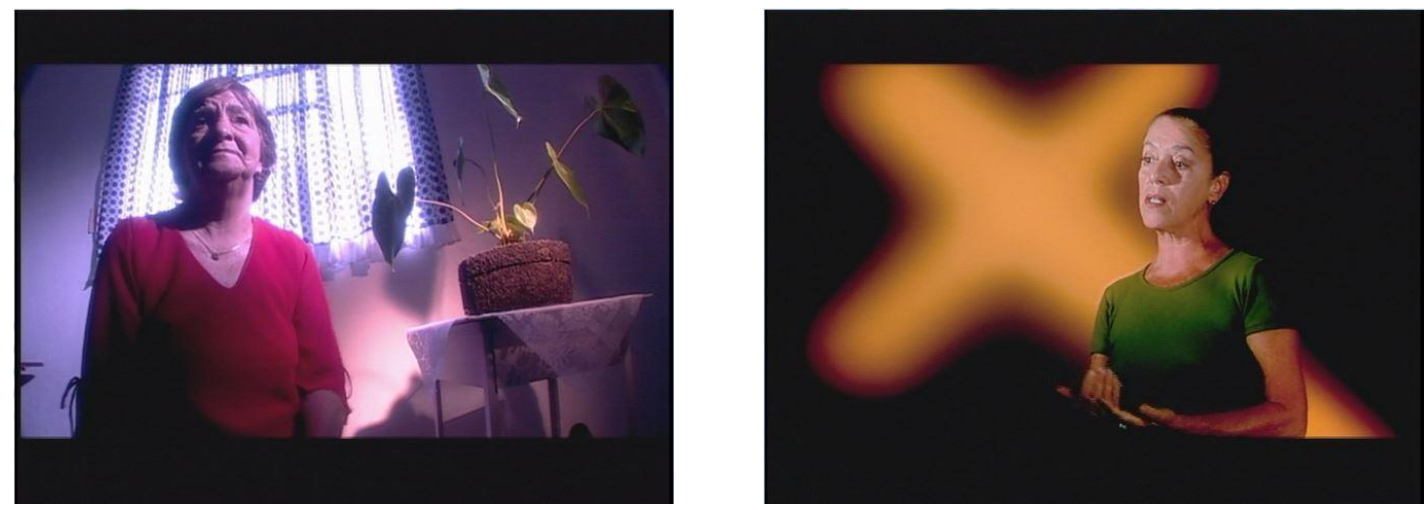

Figura 1 - Narrativa utilizada no documentário: testemunhos e aporte teórico sobre o rito. Fonte: Elaborado pelo Autor (2015)

Por liberdade poética, o diretor inseriu no roteiro um momento de reconstituição que narra a prática do ritual por um menino (Joaquim). Ao inserir este momento de reconstituição, o filme perde o seu caráter totalmente documental e apropria-se da linguagem ficcional para retratar este momento do roteiro. Abaixo (figura 2), algumas das cenas ficcionais do documentário onde se observa um grande número de atores/atrizes e figurantes. . 

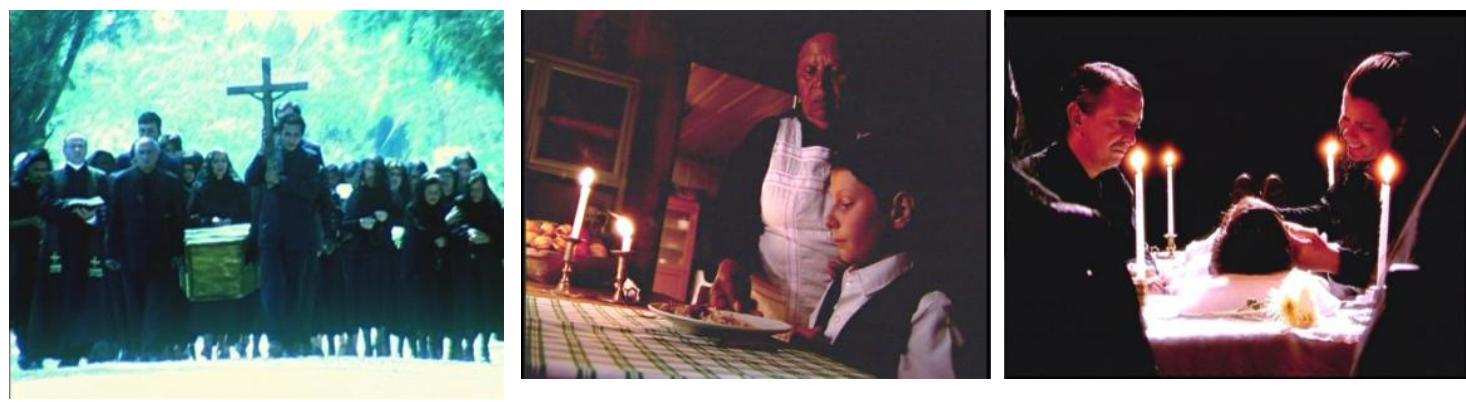

Figura 2 - Cenas ficcionais do documentário "A Coberta d'Alma - Um ritual para os mortos de Osório". Fonte: Elaborado pelo Autor (2015)

Para este momento do roteiro onde acontece a reconstituição da prática do ritual da Coberta d'Alma, a equipe de direção optou pela ambientação em outra época, que não a atual; percebe-se essa mudança no tempo por meio dos figurinos, pelos elementos de cena e pelas locações, que remetessem a uma vida na cidade de Osório na década de 1970.

As falas seguem uma linha cronológica do processo de realização do ritual da Coberta d'Alma, intercalada por um narrador em $o f f .{ }^{4} \mathrm{O}$ documentário acaba por ocupar uma posição ambígua, pois, se por um lado recorre a procedimentos próprios desta forma de fazer audiovisual (escolha dos planos, enquadramento, iluminação, montagem, sequência lógica dos fatos), por outro lado procura manter uma relação de proximidade muito grande com a realidade; isso acontece por que este gênero respeita determinado conjunto de convenções, recursos característicos do documentário, que garantem autenticidade ao que é documentado.

\section{A trilha sonora}

No sentido de analisar a produção audiovisual do gênero documentário, é muito importante perceber o papel da trilha sonora para a contextualização dos elementos que formam o filme. Nesse sentido, o som serve para envolver o discurso do documentário numa atmosfera de sentimentalidade, saudosismo e reflexão.

O documentário "A Coberta d'Alma, um ritual para os mortos de Osório" teve a sua trilha sonora original criada pelo músico gaúcho Geraldo Flach; além da trilha que

\footnotetext{
${ }^{4}$ A voz off é proferida por alguém fora do campo visual em questão. No caso deste documentário, serve para contextualizar as informações aos espectadores.
} 
faz a ligação entre as cenas do documentário há uma participação do Grupo Vocal FEEVALE entoando a "Canção da Despedida", música fúnebre do folclore brasileiro. Além disso, no decorrer do documentário é entoada uma "Incelença", que são canções fúnebres de encaminhamento da alma da pessoa falecida ao reino dos Céus. No documentário a Incelença à Virgem do Rosário é a canção serve de fundo para a cena na reconstituição onde o menino Joaquim está vestindo a Coberta d'Alma do seu amigo José.

Uma das principais funções da trilha sonora na produção audiovisual é de unir os elementos do roteiro de modo a fazer as pontes necessárias, constituindo uma unidade fílmica e linear, sem rupturas. Nota-se uma articulação forte entre sons e imagens, e muito disso se deve ao próprio caráter dramático do tema a que o documentário se refere: um rito funerário, de perpetuação da memória de um ente falecido no seu contexto familiar e social, realizado por meio do ato de vestir uma roupa (que pode ter pertencido ao morto ou comprada nova para a ocasião) e que fortalece as relações por gerações.

Desse modo, classifico o documentário “A Coberta d'Alma - Um ritual para os mortos de Osório" como uma tentativa de reconstrução histórica da memória da prática deste rito funerário entre os moradores da cidade de Osório/RS e localidades adjacentes. Memórias estas que falam de um tempo não muito distante, de relações de afeto ou de parentela muito significativas e que busca a lembrança afetiva dessas pessoas que, por meio da sua crença na perenização da memória do seu ente falecido, realizam o ritual da Coberta d'Alma.

A memória é um campo de representações e sensibilidades que busca para si a imaginação e uma imagem do passado. Não se faz necessário encontrar provas que validem ou não as memórias e histórias narradas por esses personagens ao testemunharem a prática da Coberta d'Alma. Antes de testemunharem somente sobre a prática deste rito, falam de si, da sua formação, da sua trajetória de vida e dos seus percursos enquanto moradores/as da cidade de Osório/RS. Falam de deslocamentos e reencontros, de tradição e modernidade, de memória e de esquecimento; mas, sobretudo, falam de lembrar (e muito intimamente) desejam manter viva a memória daquele/a ente falecido, por meio da prática da Coberta d'Alma. 


\section{Ficha Técnica}

\section{A COBERTA D'ALMA - UM RITUAL PARA OS MORTOS DE OSÓRIO}

Casanova Filmes, 2004. 1 DVD (52 min+créditos), NTSC, color.

Roteiro e Direção: Hique Montanari

Roteiro baseado na monografia "Uma ambivalência na Coberta d'Alma", de Marina

Raymundo da Silva

Direção de Fotografia: Jorge Henrique Boca

Direção de Arte: Iara Noemi e Gilka Vargas

Produção Executiva: Karine Emerich

Coordenação de Produção: Cíntia Helena Rodrigues

Direção de Produção: Janaína Fischer

Trilha Sonora Original: Geraldo Flach

Narração: Carlos Cunha

Produção de Elenco: Ana Horn

Assistente de direção: Thiago Martini

Montagem: Hique Montanari

Coprodução: Hique Montanari / Casanova Filmes / Fundação Cultural Piratini - TVE RS / TV Cultura de São Paulo

Gerência do Núcleo de Documentários da TV Cultura: Mario Borgneth

Recebido em: 19/03/2015

Aprovado em: 20/05/2015 